\title{
Herpes zoster com complicações em pacientes idosos
}

\author{
Herpes zoster with complications in elderly patients \\ Herpes zoster con complicaciones en pacientes ancianos
}

Recebido: 23/07/2021 | Revisado: 30/07/2021 | Aceito: 03/08/2021 | Publicado: 08/08/2021

\author{
Mariana Silva Barros \\ ORCID: https://orcid.org/0000-0001-9298-7196 \\ Universidade Federal de Sergipe, Brasil \\ E-mail: marianab.odonto@gmail.com \\ Janaína Alves Benício \\ ORCID: https://orcid.org/0000-0002-4013-4906 \\ Universidade Federal da Paraíba, Brasil \\ E-mail: janabenicio82@gmail.com \\ Lino João da Costa \\ ORCID: https://orcid.org/0000-0001-5861-1339 \\ Universidade Federal da Paraíba, Brasil \\ E-mail: linoj@uol.com.br \\ Paulo Rogério Ferreti Bonan \\ ORCID: https://orcid.org/0000-0002-4449-4343 \\ Universidade Federal da Paraíba, Brasil \\ E-mail:pbonan@yahoo.com \\ Daniel Furtado Silva \\ ORCID: https://orcid.org/0000-0003-3319-2996 \\ Universidade Federal da Paraíba, Brasil \\ E-mail: furtado.ds@gmail.com \\ Ana Carolina Lyra de Albuquerque \\ ORCID: https://orcid.org/0000-0002-6532-5020 \\ Universidade Federal da Paraíba, Brasil \\ E-mail: lina.lyra@gmail.com \\ Maria Sueli Marques Soares \\ ORCID: https://orcid.org/0000-0003-0712-8456 \\ Universidade Federal da Paraíba, Brasil \\ E-mail: msuelimarques@gmail.com
}

\section{Resumo}

Herpes Zoster (HZ) é uma infecção aguda causada pelo vírus varicela-zoster, quando ocorre reativação do mesmo que está latente em células nervosas de indivíduos que tiveram varicela. O mecanismo da reativação viral ainda é desconhecido, porém acredita-se que esteja relacionado com algum tipo de deficiência na imunidade. A doença afeta mais comumente indivíduos imunossuprimidos e idosos. Clinicamente se caracteriza por lesões vesículo- bolhosas distribuídas na região inervada pelo nervo afetado, causando dores intensas. Este artigo relata dois casos em pacientes idosos que se queixavam de lesões bucais e cutâneas com sintomatologia dolorosa. Em ambos os casos as lesões envolviam o nervo trigêmeo e evoluíram apresentando complicações como a Neuralgia Pós-Herpética e a Síndrome de Ramsay Hunt. Foi prescrito antiviral, analgésico, antibiótico e laserterapia. Em nenhum dos casos ocorreu recidiva no espaço de proservação de 3 anos. O cirurgião-dentista precisa estar atento às lesões vesículo - bolhosas que acometem a pele e as mucosas de forma unilateral, acompanhadas de sintomas de prurido e dor, especialmente em idosos, por apresentarem risco aumentado de desenvolver HZ com complicações e necessidade de hospitalização.

Palavras-chave: Herpes Zoster; Vírus da Varicela-Zoster; Envelhecimento; Geriatria; Nevralgia.

\begin{abstract}
Herpes Zoster (HZ) is an acute infection caused by the varicella-zoster virus, when it reactivates latent in nerve cells of individuals who have had chickenpox. The mechanism of viral reactivation is still unknown, but it is believed to be related to some type of immunity deficiency. The disease most commonly affects immunosuppressed and elderly individuals. Clinically, it is characterized by vesiculobullous lesions distributed in the region innervated by the affected nerve, causing severe pain. This article reports two cases in elderly patients who complained of oral and cutaneous lesions with painful symptoms. In both cases the lesions involved the trigeminal nerve, with hearing impairment. The cases evolved with complications such as Postherpetic Neuralgia and Ramsay Hunt Syndrome. Antiviral, analgesic, antibiotic and laser therapy were prescribed. In none of the cases there was a recurrence within the 3-year follow-up period. Dental surgeons need to be aware of vesicular lesions - bullous that affect the skin and mucous membranes unilaterally, accompanied by symptoms of itching and pain, especially in the elderly, as they are at increased risk of developing $\mathrm{HZ}$ with complications and need for hospitalization.
\end{abstract}


Keywords: Herpes Zoster; Varicella Zoster Virus; Aging; Geriatrics; Neuralgia.

\section{Resumen}

El herpes zoster (HZ) es una infección aguda causada por el virus varicela-zoster, cuando se reactiva latente en las células nerviosas de personas que han tenido varicela. El mecanismo de reactivación viral aún se desconoce, pero se cree que está relacionado con algún tipo de deficiencia inmunitaria. La enfermedad afecta con mayor frecuencia a personas inmunodeprimidas y de edad avanzada. Clínicamente se caracteriza por lesiones vesiculobullosas distribuidas en la región inervada por el nervio afectado, que provocan dolor severo. Este artículo reporta dos casos en pacientes ancianos que se quejaron de lesiones orales y cutáneas con síntomas dolorosos. En ambos casos, las lesiones afectaron al nervio trigémino, presentaron discapacidad auditiva. Los casos evolucionaron con complicaciones como la neuralgia posherpética y el síndrome de Ramsay Hunt. Se prescribió terapia antiviral, analgésica, antibiótica y láser. En ninguno de los casos hubo recurrencia dentro del período de seguimiento de 3 años. Los cirujanos dentistas deben estar atentos a las lesiones vesiculares: ampollosas que afectan la piel y las membranas mucosas de manera unilateral, acompañadas de síntomas de picazón y dolor, especialmente en los ancianos, ya que tienen un mayor riesgo de desarrollar $\mathrm{HZ}$ con complicaciones y necesidad de hospitalización.

Palabras clave: Herpes Zoster; Virus de la Varicela Zóster; Envejecimiento; Geriatría; Neuralgia.

\section{Introdução}

O vírus varicela-zoster (VZV) é um herpesvírus humano patogênico que causa a varicela (catapora) como infecção primária, após a qual se torna latente dentro dos neurônios ganglionares ao longo de todo o neuroeixo, podendo sofrer processo de reativação e se manifestando clinicamente como o Herpes Zoster (HZ) (Ghaznawi et al., 2011; Levin, 2012).

O HZ é um problema de saúde pública que pode afetar indivíduos de qualquer idade, porém é mais frequente em pessoas idosas, imunocomprometidas e em uso de imunossupressores (Koshy et al 2018). Um estudo de revisão sistemática evidenciou que a incidência do $\mathrm{HZ}$ aumenta com a idade. $\mathrm{O}$ autor constatou que a incidência da doença era de 5 a 8/1000 novos casos entre pessoas com 50 anos ou mais de idade, passando para 11/1000 entre aquelas com 75 ou mais anos. (Mareque 2019).

O declínio da imunidade celular específica (Kennedy et al., 2020) observado no envelhecimento humano e em estado de imunodepressão (Pipovar et al., 2013), são as principais condições que aumentam o risco de reativação do VZV, porém também há outras condições que podem desencadear o referido processo como: situação de extremo estresse, neoplasias malignas e abuso de álcool (Arwin, 1996; Lasserre et al., 2012; Gupta et al., 2013).

Parece haver unanimidade entre autores ao afirmarem que a imunossenescência é um fator que contribui para que a doença HZ apresente maior incidência entre indivíduos idosos (Ghaznawi et al., 2011; Levin, 2012; Tseng et al., 2012) e nesta população, a evolução clínica da doença pode ocorrer com várias complicações. A Neuralgia Pós-herpética é a complicação mais comum e se caracteriza por dor persistente na região afetada pelo HZ, enquanto que a Síndrome de Ramsay Hunt, quando há comprometimento do ouvido e paralisia de Bell, é uma complicação mais rara (Almeida, 2020).

O contingente idoso no Brasil, atualmente representa mais de 29 milhões de pessoas na faixa etária de 60 anos ou mais, correspondendo a $14 \%$ da população do país e, com perspectivas de dobrar este percentual nas próximas décadas (IBGE, 2018). O crescente envelhecimento da população e a morbilidade associada ao HZ torna importante a discussão do tema com abordagem para o cirurgião dentista, visando o diagnóstico precoce e prevenção de complicações associadas e de hospitalização. O presente artigo descreve dois casos de $\mathrm{HZ}$ em idosos que apresentaram complicações associadas à doença.

\section{Metodologia}

Foi realizado estudo observacional, retrospectivo e descritivo, sendo apresentado no formato de Relato de Casos Clínicos (Lüdke \& André, 2013; Koche, 2011) e, cujos pacientes procuraram atendimento na clínica de Estomatologia de um curso de odontologia. Os dados epidemiológicos, história da doença e registros fotográficos, foram coletados através dos prontuários dos dois pacientes, após a autorização dos mesmos mediante assinatura do Termo de Consentimento Livre e 
Esclarecido (TCLE), seguido as recomendações de ética da Declaração de Helsinque (1984), bem como os preceitos da publicação sem a identificação dos pacientes.

\section{Relato dos Casos}

\section{Caso 1}

Paciente do sexo feminino, 62 anos, compareceu à Clínica de Estomatologia da Universidade Federal da Paraíba, com queixa de sintomatologia dolorosa provocada por lesões na língua e lábio inferior. Durante anamnese a paciente afirmava ter buscado atendimento médico, sem sucesso no diagnóstico e negava qualquer morbidade sistêmica. Ao exame físico extraoral foram observadas crostas cutâneas nas regiões mentoniana, zigomática e comissura labial do lado esquerdo. (Figuras 1A, 1B, 1C). No vermelhão do lábio, do lado esquerdo havia lesões ulceradas (Figura 1C). Intraoralmente observou-se extensa área eritematosa de erosão e áreas ulceradas, distribuídas no dorso lingual e borda lateral da língua do mesmo lado das lesões de pele, no entanto sem ultrapassava a linha média lingual (Figura 1D). Considerando o quadro clínico apresentado se estabeleceu diagnóstico clínico de HZ, sendo instituído tratamento com droga antiviral e antipirético/analgésico.

Uma vez que a paciente também referia sintomatologia dolorosa no ouvido do lado esquerdo, foi solicitada avaliação do otorrinolaringologista que constatou de perda auditiva. Após uma semana a paciente retornou para avaliação, sendo observada remissão quase completa das lesões bucais e de pele (Figuras 2A e 2B), nesta ocasião, a paciente referiu dor persistente na região cutânea da face do lado afetado, sendo considerado o diagnóstico de nevralgia pós- herpética. Foi indicado e executado tratamento com Laser de baixa intensidade e observada uma melhora da sintomatologia, após algumas sessões.

Figura 1. Lesões do HZ (A, B, C). Lesão erosiva e ulcerada em língua sem ultrapassar a linha média (D).

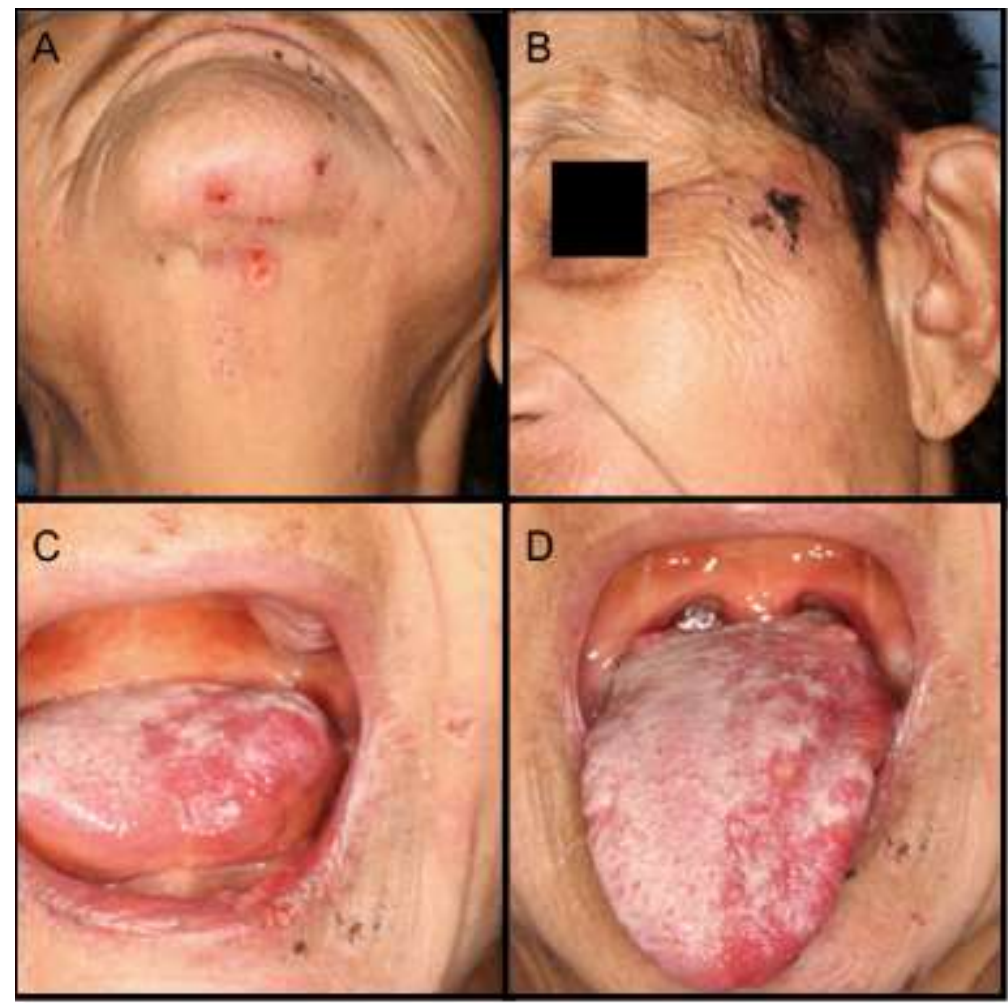

Fonte: Autores. 
Figura 2. Remissão da doença, presença de manchas cutâneas na região de cicatriz das lesões.

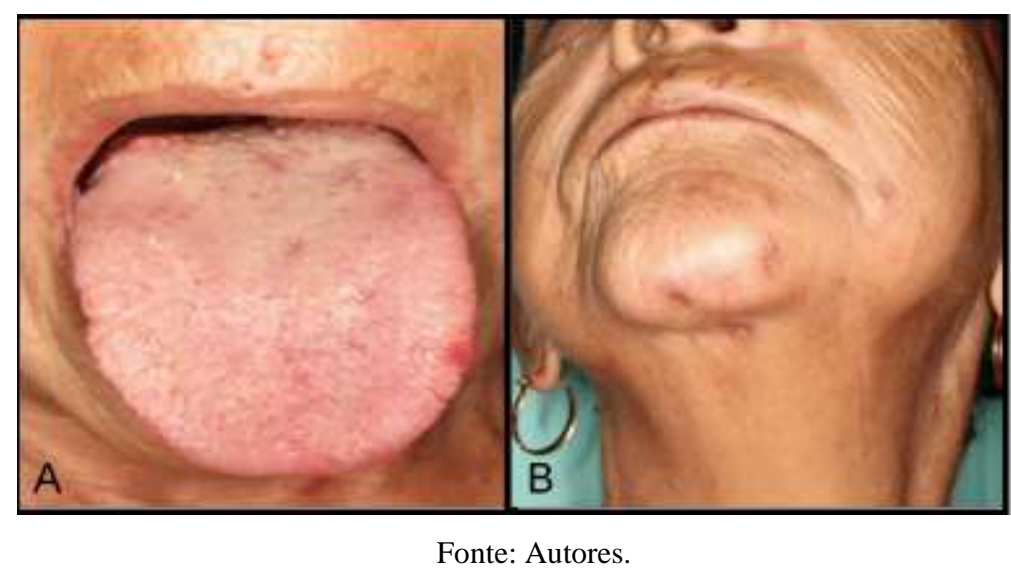

\section{Caso 2}

Paciente do sexo masculino, 62 anos, procedente do interior, procurou atendimento na Clínica de Estomatologia da Universidade Federal da Paraíba, se queixando de lesão facial e intensa dor, com evolução de 22 dias. O mesmo referiu que na primeira semana teve febre e prostração e que foi medicado com analgésico, em consulta médica. Durante exame físico extraoral se observou assimetria facial, com tumefação do lado esquerdo e, presença de crostas cutâneas na face, atingindo desde a região de ouvido externo até a comissura labial do lado esquerdo. (Figura 3A, 1B). Intraoralmente havia área ulcerada recoberta de exudato, na região de gengiva inserida inferior, anterior, próxima aos elementos dentários. (Figura 3C). Todas as lesões apresentavam sintomatologia dolorosa e o paciente também referia dor espontânea no ouvido do lado esquerdo. Também foram observadas lesões e exudato purulento no pavilhão auditivo externo (Figura 3D). Considerando o quadro clínico apresentado foi estabelecido diagnóstico clínico de HZ, sendo instituído tratamento com medicamentos antiviral, antipirético/analgésico/antibioticoterapia. Foi solicitada avaliação da função auditiva. Após 10 dias o paciente retorna para avaliação, sendo observada remissão completa da lesão bucal e de pele (Figura 4 A, B e C), no entanto foi observada paralisia facial do lado afetado pela doença (Figura 4D), com o registro desta manifestação clínica foi sugerido o diagnóstico de Síndrome de Ramsay Hunt, considerando que o paciente havia apresentado comprometimento auditivo. O paciente foi encaminhado para fisioterapia. 
Research, Society and Development, v. 10, n. 10, e208101018654, 2021

(CC BY 4.0) | ISSN 2525-3409 | DOI: http://dx.doi.org/10.33448/rsd-v10i10.18654

Figura 3. Aspectos clínicos de lesões cutâneas e bucais do HZ, durante a primeira consulta.

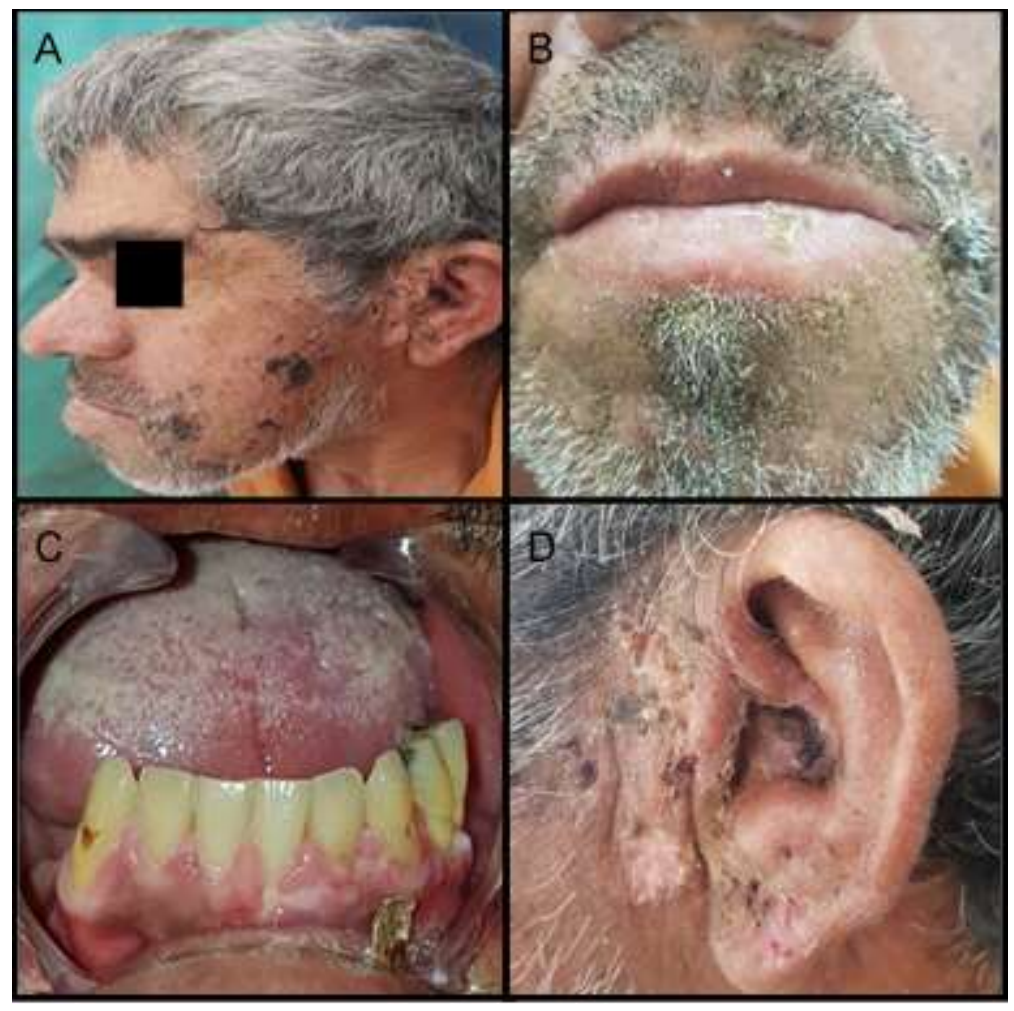

Fonte: Autores.

Figura 4. Aspecto clínico após tratamento (A, B). Notar paralisia facial do lado esquerdo (Paralisia de Bell) (C, D).

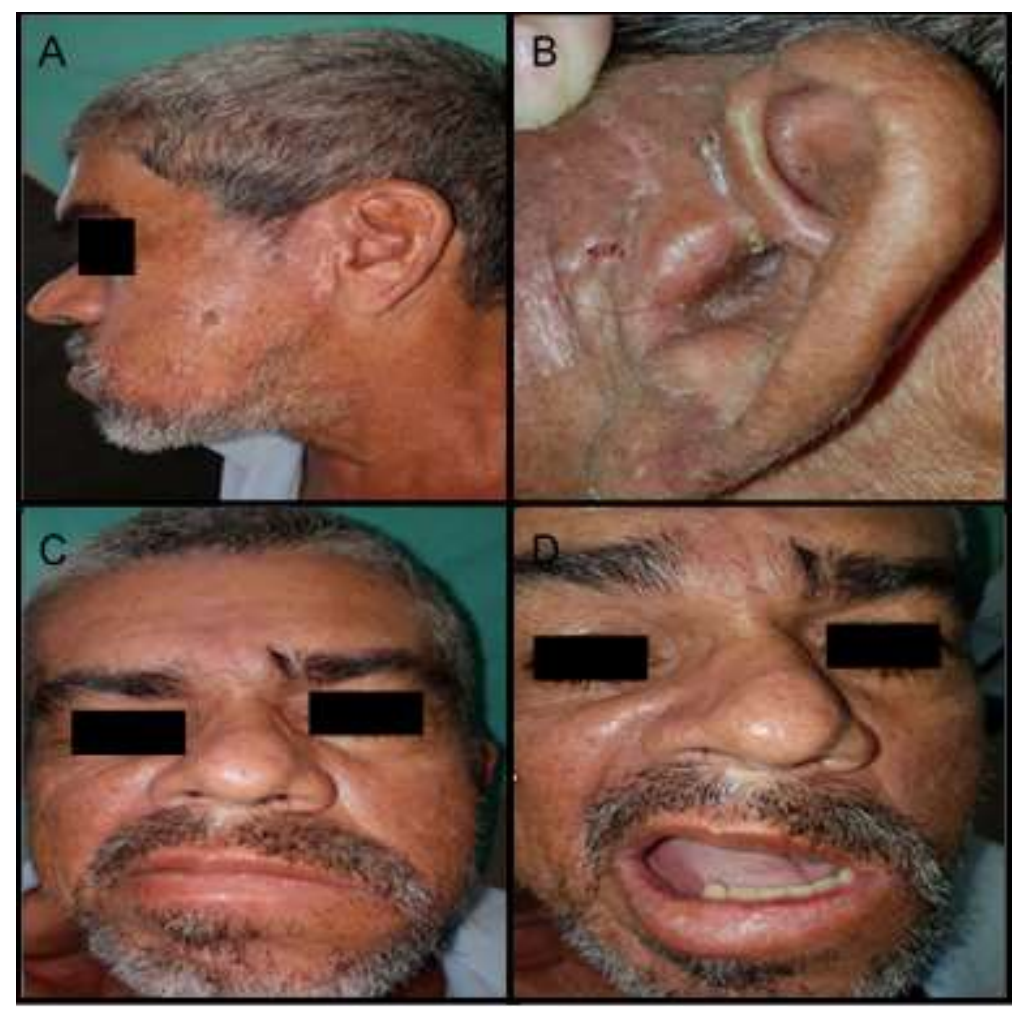

Fonte: Autores. 


\section{Discussão}

Embora o mecanismo de reativação do vírus da Varicela Zoster (VVZ) ocasionando o HZ ainda seja pouco compreendido, acredita-se que está relacionado com algum tipo de deficiência na imunidade presente em determinados grupos de pessoas, tais como pacientes HIV positivos, pacientes submetidos a terapias imunossupressoras (Arruda et al., 2016) observando correlação com idade e hospitalização (Studahl, Petzold \& Cassel, 2013). Por outro lado, quando não se determina qualquer alteração sistêmica específica no HZ, pode-se considerar o estresse como fator desencadeante (Arruda et al., 2016, Arwin, 1996), bem como a possibilidade de tratamento com drogas citotóxicas e abuso de álcool (Lasserre et al., 2012; Gupta et al., 2013). Nos casos ora apresentados os pacientes eram idosos e o único fator que favorecia a reativação viral era a imunossenescência. Além de que em ambos os casos houve complicação, o que reforça o achado de Tseng et al., (2012) que afirmam que em idosos, o HZ causa maiores complicações, maior número de hospitalização e mortalidade (Tseng et al., 2012).

No caso 1, após desaparecer os sinais e sintomas do HZ, a paciente retornou ao Serviço se queixando de dor persistente na face do lado afetado, sendo sugerido o diagnóstico de neuralgia pós-herpética (NPH), que se caracteriza pela persistência de dor durante mais de 3 meses após a resolução completa das lesões cutâneas do HZ, podendo persistir durante vários meses e anos (Soyuncu et al., 2009), esta complicação pode ocorrer em cerca de 22\% dos casos de HZ (Pentikins et al 2011). A paciente foi submetida a sessões de laserterapia apresentando melhora. A laserterapia de baixa intensidade tem sido utilizada com comprimento de onda (780-980nm), por se entender que atua induzindo alterações teciduais através da modulação de mecanismos inflamatórios e excitatórios periféricos. Envolvendo a estimulação de citocinas anti-inflamatórias, fatores de crescimento e aumento de trifosfato de adenosina (ATP), tais mecanismos podem ser essenciais para a resposta favorável amenizando a sensibilidade dolorosa e o reparo neural de pacientes com HZ (Spátola, 2010).

No segundo caso apresentado, a complicação ocorreu conjuntamente com os sinais e sintomas do HZ, onde foi constatada infecção do nervo facial e auditivo provocando lesões na região da orelha, com exudato no canal auditivo e perda da audição. Após desaparecer os sintomas do HZ, o paciente retorna ao serviço apresentando paralisia periférica facial ou paralisia de Bell (Soyuncu et al., 2006). Considerando o quadro clínico que neste paciente apresentou na primeira consulta, foi sugerido o diagnóstico de Síndrome Ramsay-Hunt, também conhecida como herpes zoster auricular e seu diagnóstico é essencialmente clínico (Khan \& Fatema, 2020). Ressalta-se a necessidade de um exame clínico detalhado atentando para sinais de paralisia facial e comprometimento auditivo,

Autores destacam a importância da capacidade dos profissionais de saúde em reconhecer os sinais e sintomas clínicos locais e sistêmicos, bem como as possíveis complicações relacionadas ao HZ. Particularmente quando a doença envolve a face parece que há menos conhecimento difundido, levando a menos diagnosticado ou ao diagnosticado tardio. A importância do diagnóstico precoce do $\mathrm{HZ}$ reside em poder iniciar o tratamento terapêutico nas primeiras fases da doença, reduzindo a dor e o prurido, melhorando a sintomatologia, a duração da manifestação e a qualidade de vida do paciente acometido (Guimarães et al, 2021).

Uma importante característica para o diagnóstico do HZ com manifestação na cavidade bucal é a presença de lesões na mucosa sem ultrapassam a linha média, e isto ocorre porque o nervo trigêmeo não se cruza com seu homólogo contralateral (Arruda et al., 2016; Prest, Melo, Sá, Carneiro, Bernardino, Feitosa, 2021), tal característica foi observada nos casos aqui apresentados.

\section{Considerações Finais}

Considerando o elevado índice de envelhecimento da população e a maior probabilidade de acometimento do contingente idoso pelo HZ, ressalta-se a importância da atuação do cirurgião-dentista no diagnóstico da doença, atentando para a presença de lesões vesículo-bolhosas que acometem a pele e as mucosas de forma unilateral, acompanhadas de sintomas de 
prurido e dor, uma vez que o diagnóstico precoce pode contribuir para redução do risco de complicações e da necessidade de hospitalização.

Estabelecer estratégias de prevenção do $\mathrm{HZ}$ em idosos é um aspecto importante e tem sido recomendado incluir vacinação contra o $\mathrm{HZ}$ para pessoas com 50 anos ou mais, ao mesmo tempo em que novas alternativas de vacinas surgem no cenário da pesquisa clínica e laboratorial. O tema ainda traz divergências entre autores, sendo portanto importante avaliar criticamente as melhores evidências disponíveis sobre a eficácia e segurança destas vacinas, o que se configura um campo para estudos envolvendo o $\mathrm{HZ}$ em pessoas idosas.

\section{Referências}

Almeida, U. T. F. H., Silva, R. A., Almeida, A. H., \& Nunes, L. M. A. (2020). Síndrome de Ramsay Hunt: uma revisão sistemática. REAS/EJCH, 55, e3899.

Arruda, J. A. A., Radnai, J. L. P. B., Silva, L. V. O., Souza Neta, I. F., Figueiredo, E. L., Alvares, P. R., \& Silveira, M. M. F. (2016). Zoster with Trigeminal Nerve Damage: Case Report. Rev. cir. traumatol. buco-maxilo-fac, 16 (4)

Arwin, A. M. (1996). Varicella-zoster virus. Clin. Microbiol.,9(3)361-381.

Ghaznawi, N. et al. (2011). Herpes zoster ophthalmicus: Comparison of disease in patients 60 years and older versus younger than 60 years. Ophthalmology, $118(11), 2242-2250$.

Guimarães F. et al. (2021). How to identify a oral manifestation of Herpes-Zoster? Research, Society and Development,10(2), e31610212617, 2021.

Gupta, S., Gupta S., Thomas, M., Mahendra, A., Jindal, N., Bhaskar, G., \& Aggarwal, M. (2013). Herpes Zoster with disseminated lesions. What is it? J Med Life, 6(1), 84-5.

IBGE. Brasil. Censo demográfico. 2018

Lasserre, A., Blaizeau, F., Gorwood, P., Bloch, K., Chauvin, P., Liard, F., Blanchon, T., \& Hanslik, T. (2012). Herpes zoster: family history and psychological stress-case-control study. J Clin Virol, 55(2),153-7.

Levin, M. J. (2012). Immune senescence and vaccines to prevent herpes zoster in older persons. Curr Opin Immunol. 24(4), 494-500.

Ludke, M., \& Andre, M. E. D. A. (2013). Pesquisas em educação: uma abordagem qualitativa. São Paulo: E.P.U

Mareque, M., Oyaguiez I., Morano, R., \& Casado, M. A. (2019). Systematic review of the evidence on the epidemiology of herpes zoster: incidence in the general population and specific subpopulations in Spain. Public Health.167, 136-46.

Khan, Y. M. T., \& Fatema, N. (2019). Ramsay Hunt syndrome. Pan Afr Med J. 16 (34), 201.

Kennedy, P. G. E., Graner, M. W., Gunaydin, D., Bowlin, J., Pointon, T., \& Yu, X. (2020). Varicella-Zoster Virus infected human neurons are resistant to apoptosis. J Neurovirol. 26, 330-337.

Koche, J. C. (2011). Fundamentos de metodologia científica. Petrópolis: Vozes. Disponível em: http://www.brunovivas.com/wpcontent/uploads/sites/10/2018/07/K\%C3\%B6che-Jos\%C3\%A9-Carlos0D0AFundamentos-de-metodologia-cient\%C3\%ADfica-_teoria-da0D0Aci\% C3 \%AA ncia-e-inicia\%C3\%A7\%C3\%A3o-\%C3\%A0-pesquisa.pdfhttps://repositorio.ufsm.br/bitstream/handle/1/15824/Lic_Computacao_Metodologia-Pesq uisa-Cien tifica.p df? sequence $=1$

Koshy, E., Mengting, L., Kumar H, \& Jianbo, W. (2018). Epidemiology, treatment and prevention of herpes zoster: A comprehensive review. Indian J Dermatol Venereol Leprol. 84 (3), 251-262.

Pentikis, H. S., Matson, M., Atiee, G., Boehlecke, B., Hutchins, J. T., Patti, J. M., et al. (2011). Pharmacokinetics and safety of FV-100, a novel oral anti-herpes zoster nucleoside analogue, administered in single and multiple doses to healthy young adult and elderly adult volunteers. Antimicrob Agents Chemother. 55, 2847-54.

Pivovar, L., Cossul, M. F., Melo, J. R., Gil F. B. D., \& Lima, A. A. S. Herpes-zóster com manifestação bucal em paciente imunossuprimido: relato de caso. Archives of Oral Research. 9 (2),135-140.

Prest, V. T., Melo, R. B., Sá, C. D. L., Carneiro, N. C. M., Bernardino, R. de S., \& Feitosa, V. P. (2021). Clinical report of rare manifestation of Herpes Zoster in the mandibular nerve. Research, Society and Development,.10 (4), e46010414225.

Soyuncu, S., Berk, Y., Eken, C., Gulen, B., \& Oktay, C. (2009). Herpes zoster as a useful clinical marker of underlying cell-mediated immune disorders. Ann Acad Med Singapore, 38, 136-138.

Spátola, A. (2010). Neuralgia pós-herpética - tratamento da dor neuropática com uso da toxina botulínica tipo A - apresentação de um caso. Med Reabil, 29(3),74-5.

Studahl, M., Petzold, M., \& Cassel, T. (2013). Disease burden of herpes zoster in Sweden--predominance in the elderly and in women - a register based study. BMC Infect Dis, 13(1), 586.

Tseng, H. F., Chi, M., Smith, N., Marcy, S. M., Sy, L. S., \& Jacobsen, S. J. (2012). J Infect Dis, 206, 190-6. 